\title{
ASSESSING THE CONTRIBUTION OF URBAN FREIGHT TERMINALS IN LAST MILE OPERATIONS
}

\author{
Eftihia Nathanail ${ }^{1}$, Michael Gogas ${ }^{2}$, Giannis Adamos ${ }^{3}$ \\ ${ }^{1}$ University of Thessaly, Department of Civil Engineering \\ Pedion Areos, 38334 Volos, Greece \\ Ph.: +302421074164. Fax: +302421074131. E-mail: enath@uth.gr \\ ${ }^{2}$ University of Thessaly, Department of Civil Engineering \\ Pedion Areos, 38334 Volos, Greece \\ Ph.: +302421074158. Fax: +302421074131.E-mail: michalisgogas@uth.gr \\ ${ }^{3}$ University of Thessaly, Department of Civil Engineering \\ Pedion Areos, 38334 Volos, Greece \\ Ph.: +302421074158. Fax: +302421074131. E-mail: giadamos@civ.uth.gr
}

\begin{abstract}
This paper introduces a multi-stakeholder multi-criteria evaluation framework, which can be used for the assessment of the last mile distribution performance of urban freight terminals. To this end, a comparative analysis is conducted addressing two Greek urban intermodal freight terminals located at the port of Thessaloniki (ThPA) and Kuehne+Nagel $(\mathrm{K}+\mathrm{N})$ 's premises. The assessment of the terminals' performance relies on a tailored multi-criteria Key Performance Indicator (KPI)-based evaluation framework, whereas the selection and significance of the incorporated criteria and KPIs is predetermined by the relevant responsible stakeholders, who imposed their viewpoint through an analytic hierarchy process. Results showed that ThPA was ranked first according to its performance pertaining to the role of an intermodal interchange; still, K+N's performance index was only $8.5 \%$ lower than ThPA's, while in specific KPIs it seems that it performs in a better way.
\end{abstract}

Keywords: Freight terminals, last mile, key performance indicators, multi-stakeholder, multi-criteria, sensitivy analysis, AHP, PROMETHEE, GAIA

\section{Introduction}

Over the last decades, the continuous massing, mechanization and automation in the production, manufacturing and processing of goods and services due to emerging and increasing needs has led to the concentration of labor force around urban industrial and commercial working areas. This, in turn, forged the modification of the socioeconomic profile causing a considerable boost in urbanism trends. Statistical data indicate that more than 100 million people have migrated to cities globally since the beginning of this decade. According to the United Nations (UN), 3.9 billion people (54 per cent) of the world's population lives in urban areas, up from 746 million in 1950. Projections indicate that urbanization combined with the overall growth of the world's population could add another 2.5 billion people to urban populations by 2050 , i.e. at least $70 \%$ of world population will live in cities. Furthermore, the UN notes that the number of megacities of ten million or more inhabitants has increased from 10 in 1990 to 28 in 2014. By 2030, the world is expected to have 41 mega cities. Especially in Europe, around $75 \%$ of the population lives in urban areas (Grimm et al., 2008; Lee, 2014; European Commission, 2014; European Center for Government Transformation, 2015).

It is believed that the twenty-first century will be a century of urbanization, since growing cities attract people due to the fact that more educational and leisure activities take place and there are more opportunities for finding a job. In this regard, the problem of the supply of goods within urban context gained importance and, in turn, city logistics have proven as a great challenge. That is why the EU's interest is focused on the promotion and funding of sustainable urban mobility plans incorporating all the freight activities which coexist and co-act with passenger transport within the same transportation network, resulting mainly in traffic problems and environmental impact deteriorating the citizens' quality of life.

As the total number and concentration of the world's population in urban areas has grown, so has the importance of transporting and delivering the consumer goods required to sustain these urban areas. One of the main drivers of urban freight transport has been the continued urbanization of the world's population. Urban Freight Distribution constitutes the system and process by which goods are collected, 
transported and distributed within urban environments. Urban freight distribution is essential to supporting international and domestic trade as well as the daily needs of local businesses and consumers, including freight transportation to and from warehouse/distribution centres, retail stores, businesses, and homes. Urban freight distribution also involves transportation from freight generating facilities such as seaports, airports, railyards, manufacturing facilities and warehouse/distribution centres, many of which are located in urban areas and utilize an urban region's roadway and railway network to transport goods.

All involved stakeholders, facilities, services and networks from origin to final destination are incorporated within a supply chain. A supply chain is a system of organizations, people, activities, information and resources involved in moving a product or service from supplier to customer. Supply chain activities involve the transformation of natural resources, raw materials, and components into a finished product that is delivered to the end customer. In sophisticated supply chain systems, used products may reenter the supply chain at any point where residual value is recyclable. Supply chains link value chains (Perez, 2013).

Last mile is a term used in supply chain management and transportation planning to describe the movement of people and goods from a transportation hub to a final destination in the home. Transporting goods via freight rail networks and container ships is often the most efficient and cost-effective manner of shipping. However, when goods arrive at a high-capacity freight station or port, they must then be transported to their final destination. This last leg of the supply chain is often less efficient, comprising up to $28 \%$ of the total cost to move goods. This has become known as the "last mile problem. The last mile problem can also include the challenge of making deliveries in urban areas where retail stores, restaurants, and other merchants in a central business district often contribute to congestion and safety problems (Scott, 2009; Rodrigue, 2009).

The organization and coordination of a supply chain is accomplished through logistics (city logistics in urban environment). Taniguchi et al. (1999) define city logistics as "the process for totally optimizing the logistics and transport activities by private companies in urban areas while considering the traffic environment, the traffic congestion and energy consumption within the framework of a market economy".

The purpose and contribution of this paper to the research on city logistics is to contribute to the enrichment of past experience on the assessment of the performance of freight terminals involved in last mile distribution of goods in urban context, in order to provide a decision making auxiliary tool, indicating which one of the available candidate terminals constitutes the best alternative. The tool constitutes a KPI-based terminal performance evaluation framework and is based on the multi stakeholder multi criteria concept, also adopting the analytic hierarchy process principles (Zahir, 1999; Woudsma et al, 2007; Gogas et al, 2014).

The first organized freight activities and related facilities focused on city logistics were established in the context of urban areas in the 1960's. Due to urbanization trends prevailing during that time, the first freight and logistics terminals were set up as consolidation and distribution points inside the urban web in order to satisfy the continuously growing demand generated nearby. These patterns of increasing consumption have been shaped since late 1970's and created significant demand for goods. Within the next two or three decades, given the urban sprawl and the creation of metropolitan areas with increased congestion and spatial problems emerging, many of those facilities were established near or just outside cities. In the 2000's, the modernization of city distribution techniques, namely the e-commerce, on-line delivery, as well as the need for just in time door to door real time monitored freight delivery, created the need for individual and personalized trips in the context of last mile delivery service, increasing the traffic and environmental burden. Lately, the economic recession and the continuously growing city's web attracting all business activities have reversed the decentralization efforts made from the part of the government and the local authorities favoring urbanism once again. Urban areas have been plagued by the impacts of the ongoing economic crisis to a great extent and this has resulted in changes in the urbanization trends.

Based on the findings of recent demonstrations, workshops, round tables and conferences on best urban freight solutions, the transport demand resilience for a given population and supply system, depends on the level of provided services, which, according to the SUGAR project, is correlated with the innovative, smart and integrated ICT city logistics solutions either implemented in freight assignment or during the diffusion of related data and information (BESTUFS, 2015).

Cities face adverse impacts and so countermeasures have been introduced in order to improve the urban working and living environment. Noise nuisance, severe land pressure, increased freight trips and respective environmental impacts have caused the shifting of logistics facilities and the mitigation of their activities to exurban areas (Diziain et al., 2012). The issue of urban sprawl for economic activities and especially logistics is not new. Historically, the location of logistics terminals was close to adjacent rail 
networks. Today, those terminals tend to locate as close as possible to highway networks, port and airport areas (Rodrigue, 2004; Woudsma et al., 2007).

The performance of freight terminals relies on the performance of multiple processes that are undertaken within these areas. The role and performance of interurban freight terminals affect the performance of urban distribution to a great extent, most often determining the city logistics' system structure. As far as concerns the freight terminals that are located in the suburban and interurban areas, they play a critical role regarding the goods distribution to the nearby cities as well. The freight assignments are organized in freight terminals in order for the goods to be forwarded to regional destinations more efficiently. As such, higher load factor of trucks, less traffic congestion and less environmental emissions are achieved (De Souza et al, 2014). The aforementioned outcomes are better produced when it comes to consolidation centers where different shippers and transport and logistics service providers co-operate.

Intermodal terminals constitute very important pieces of operational freight infrastructure especially for ports and long distance road to rail interchanges or supply chain nodal points. The aim of this paper is to assess the performance of two different intermodal freight and logistics terminals, a privately operated rail-road terminal and a port terminal both located in the wider metropolitan area of a Greek port-city, the city of Thessaloniki, in the light of their impacts on the urban distribution. The inland terminal is a Freight Center within the industrial area of Thessaloniki owned by Kuehne+Nagel S.A., while the second one is Thessaloniki's Port Terminal state owned and governed through the respective Port Authority. A short profile of the two alternative freight terminals is described below (Andersen et al, 2010):

- The inland intermodal freight terminal is managed and operated by a logistics service provider and forwarding company importing and exporting goods to/from Greece using extensive operational railway network ranging from South-Eastern Europe to Central Europe. The cargo that arrives at the freight terminal by train is then consolidated, organized and/or stored in the warehouse facility. Alternatively, through a cross-docking process, it is loaded on trucks and distributed to inner city area or forwarded via trucks to regional destinations using road transport.

- The port of Thessaloniki is managed by Thessaloniki Port Authority S.A. being granted the exclusive right to use and exploit the lands, buildings and facilities of Thessaloniki Port Land Zone owned by the Greek State. The port provides handling services for various types of cargo (loading, unloading, servicing and storage), shipping services (anchoring, etc.), passenger maritime services and customs services. Apart from the trucks, accessibility to the freight terminal is provided to rail wagons underpinning intermodality.

There are many methodologies or transport and logistics related network models and KPI - based methods which can be used for the comparison of different types of terminals, especially size, handling equipment, hours of operation, throughput (e.g. containers' arrivals) etc. In addition, this paper also examines the ownership and operational characteristics of the two specific intermodal terminals in the same geographical area and market. The comparison of the terminals' efficiencies and the reasons for customer and freight forwarder choice of a particular terminal is of great interest with regard overall supply chain considerations in the context of decision making from the part of the terminal users.

For the evaluation, a Multi-Criteria Assessment (MCA) method based on the Analytic Hierarchy Process (AHP) is used. The expected outcomes include a comparison of the performance of these terminals indicating the most effective one with respect to the performance criteria that are set and a case-specific discussion about the most efficient type of intermodality in order to support the last-mile distribution. The evaluation framework is based on criteria and their KPIs. Both the criteria and respective KPIs, as well as their significance (weight) in the evaluation process are selected by the stakeholders involved in the operation of the two terminals to establish a Multi Stakeholder Multi Criteria Assessment Framework used for the prioritization of the two terminals concerning their performance through pairwise comparison with each others' attributes and figures. The outcomes will underpin the transport operators' view by feeding their decision-making framework, selecting between two alternatives concerning the supply chain: the road rail (Kuehne+Nagel terminal) or the road sea service (Thessaloniki Port terminal).

The results will indicate and validate which of these freight terminals achieves higher performance concerning the assessment criteria. The results will also provide an insight regarding the performance of the transshipment process that a transport operator considers when determining the transport chain. In fact, the outcomes of the analysis could offer a useful opportunity in order to investigate some dimensions that determine the selection of the most efficient transport chain, pursuing an intermodal operational approach and adopting the view of the transport operator.

However, there are some constraints: although the transshipment and the underlying processes are crucial parts of the whole supply chain, there are also other transport legs (first mile, long-distance transport, 
last-mile, etc.) which are of utmost importance and constitute significant factors in the decision-making process. This paper aims at the comparative analysis of two transport terminals using a multi-criteria approach, facilitating the decision-making process of a transport operator but also allowing room for many other parameters to be co-factored.

Part of this work uses data that were collected within the context of CLOSER (Connecting LOng and Short distance networks for Efficient tRansport), a three-year EC co-funded research project under the 7th FP. The paper, apart from the introductory one, it is expanded within another 3 sections incorporating the following:

- The development of the methodological framework adopted concerning the terminals' analysis and pairwise comparison. In this section the description of the structuring of the AHP utilized for the weight allocation to criteria and KPIs is also provided.

- The presentation of the numerical values concerning the terminals' pairwise comparison based on the quantification of KPIs produced through the AHP. The two terminals' pairwise comparison results based on their performance indices are also depicted within this section, while the elaboration of a sensitivity analysis is conducted in order for the validation of initial results to be conducted. In the same section the justification of the two terminals' prioritization results is processed through PROMETHEE method and use of respective software, having all of the outcomes explained and commented.

- The incorporation of the most important conclusions pertaining to the terminals' pairwise comparison, in order to provide a decision making tool.

The results and findings are based on the authors' personal research and work, produced after the running of multi stakeholder multi criteria evaluation process both in EXCEL and PROMETHEE GAIA format.

\section{Method}

In order to achieve the aims of this study, a 5-step methodology was developed:

- Step 1: Determination of criteria and key performance indicators. For the performance assessment, five criteria were used: management policy, supply side performance, organizational and institutional structure, terminal properties and level of service (Järvi and Nagel, 2013). The respective KPI's are presented in Table 1.

- Step 2: Weighting of criteria and indicators, through a pairwise comparison, which resulted in eigen values that comprised the weights assigned to each criterion and KPI.

- Step 3: Quantification of the performance indicators. In this step, based on data collected by the managing companies, each performance indicator was quantified.

- Step 4: Prioritization of the terminals. The collected data was combined and, following an Analytic Hierarchy Process (AHP), terminals were prioritized.

- Step 5: Visualization of the results. With the use of a visualization software, i.e. PROMETHEE, an illustration of the integration and individual evaluation scores, was performed.

A multi-criteria evaluation process was followed for the assessment of the two terminals, based on criteria and respective KPI's, which were selected through the Delphi Method (Criteria Assess and Measure Evaluation Process) by an expert panel. The panel was constituted of the terminals' representatives and the authors, taking into consideration the availability of respective data. For comprehension reasons, both quantitative and qualitative criteria and indicators were incorporated in the data analysis.

Based on the findings of the European research project CLOSER (Christiansen et al, 2012), several KPI's were selected and grouped under the five abovementioned criteria. Additionally, a number of indicators was also incorporated, based on the authors' knowledge and experience, resulting from the European research project STRAIGHTSOL (Andersen et al, 2014) and the INTERREG III B CADSES project IMONODE (Nathanail \& Gogas, 2005; Nathanail, 2007). The numerical values of the KPIs were either accumulated as raw data through the terminals' annual reports or estimated based on information acquired by the terminals' representatives in the context of individual interviews.

Following up the quantification of each KPI, the respective grades were determined according to the grading scale adopted in CLOSER, STRAIGHTSOL and IMONODE, and were further adjusted by the terminals' representatives within the DELPHI process. In order to capture stakeholders' viewpoint and clearly define the significance of each criterion and respective KPI, the Analytic Hierarchy Process (AHP) was followed. The choice of this method, which was firstly introduced by Saaty (1972) and has been widely used in site selection (Saaty, 1977), strategy selection (Chen and Wang, 2010), sustainability evaluation (Li and $\mathrm{Li}, 2009$ ) and the evaluation of ICT usage in logistics (Nathanail et al., 2014), relied on the simplicity 
and flexibility that it provides for solving a given problem, and that it is an easy applicable methodology allowing the decision maker to precisely assess system performance.

For the needs of this study and as part of the AHP, several categories of stakeholders were invited to participate in a questionnaire survey, in order to record their viewpoints and consequently come up with the comparative weighing of the criteria and the respective KPI's. The survey was implemented during the second half of the year 2014, and various stakeholders participated: owners, e.g. managers and coordinators, infrastructure and equipment providers, users and customers, e.g. shippers, receivers, forwarders, transport and logistics service providers, stevedoring companies, transport agencies and third party logistic companies, and local state and public authorities.

Taking into account the prioritization and weighting of the criteria and the respective KPI's, the pairwise comparison of the two terminals was conducted, in order to identify which one is more efficient in terms of its services and performance. Then, the prioritization of the two terminals was tested through a sensitivity analysis, aiming at determining the degree that different values of an independent variable can affect a specific dependent variable, under a given set of assumptions. For this reason, each decision criterion's weight was increased or decreased by $10 \%$ with simultaneous counterbalance of the rest of the criteria weights, in order to investigate whether there is any modification in the terminal prioritization- and consequently achieve more objective results. In the sensitivity analysis one criterion at a time was checked.

The last step of the methodology included the illustration of the results, which was achieved with the use of PROMETHEE and GAIA software. These methods were chosen for their high applicability in multiple criteria decision making (http://www.promethee-gaia.net/vpa.html).

\section{Results}

\subsection{Terminals' comparison}

The multi criteria assessment was based on five criteria and their respective indicators. Together with their weights (Wi for criteria and wij for KPIs), which were determined by the involved stakeholders through the AHP, they are depicted in Table 1.

The criteria and their significance, as determined by the involved stakeholders, are depicted within the first two columns of Table 1. In the next seven columns, the KPIs, their explanation, their values, grades and weights are shown. The grades of the KPIs were produced based on their numerical value (see columns 5 and 6 in Table 1) and the grading scale as it was defined according to literature review (Nathanail and Gogas, 2005; Nathanail, 2007), also considering the viewpoint of the involved stakeholders (Delphi method). In particular, based on the review of available sources and the expert group's opinion, the grading scales were determined through a range of numerical values decided by the expert group after brainstorming, taking into consideration all the special characteristics and conditions in the area of study.

Table 1. Multi criteria assessment

\begin{tabular}{|c|c|c|c|c|c|c|c|c|c|c|c|}
\hline Criterion & Wi & $\begin{array}{l}\text { Indicator } \\
\text { (KPI) }\end{array}$ & Description & $\begin{array}{l}\text { Value } \\
\text { (vij) } \\
\text { ThPA }\end{array}$ & $\begin{array}{l}\text { Value } \\
\text { (vij) } \\
\mathbf{K}+\mathbf{N} \\
\end{array}$ & $\begin{array}{c}\text { Grade } \\
\text { (gij) } \\
\text { ThPA } \\
\end{array}$ & \begin{tabular}{|c|} 
Grade \\
(gij) \\
$\mathbf{K}+\mathbf{N}$ \\
\end{tabular} & wij & $\begin{array}{l}\text { Low } \\
(1-4)\end{array}$ & $\begin{array}{c}\text { Medium } \\
(5-8)\end{array}$ & $\begin{array}{c}\text { High } \\
(9-10)\end{array}$ \\
\hline \multirow{4}{*}{ 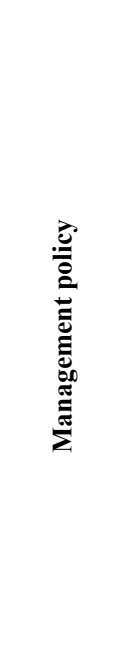 } & \multirow{4}{*}{$15 \%$} & $\begin{array}{l}\text { Multimodality } \\
\text { rate }\end{array}$ & $\begin{array}{l}\text { Percentage of } \\
\text { multimodal } \\
\text { shipments over total }\end{array}$ & $15 \%$ & $40 \%$ & 2 & 5 & $20 \%$ & $<40 \%$ & $40-80 \%$ & $>80 \%$ \\
\hline & & $\begin{array}{l}\text { Environmental } \\
\text { burden }\end{array}$ & $\begin{array}{l}\text { GHG emissions, } \\
\text { noise nuisance and } \\
\text { traffic } \\
\text { (low/medium/high) }\end{array}$ & $\begin{array}{l}\text { Very } \\
\text { high }\end{array}$ & Medium & 1 & 8 & $20 \%$ & High & Medium & Low \\
\hline & & $\begin{array}{l}\text { Human safety } \\
\text { and security }\end{array}$ & $\begin{array}{l}\text { Likelihood of } \\
\text { human losses, i.e. } \\
\text { annual number of } \\
\text { human injuries / } \\
\text { fatalities per } \\
\text { respective vehicle } \\
\text { kilometres }\end{array}$ & $\begin{array}{c}1.2 * 10- \\
6\end{array}$ & $2 * 10^{\wedge}-8$ & 1 & 4 & $40 \%$ & $>10^{\wedge}-8$ & $\begin{array}{c}\left(10^{\wedge}-9\right)- \\
\left(10^{\wedge}-8\right)\end{array}$ & $<10^{\wedge}-9$ \\
\hline & & $\begin{array}{l}\text { Infrastructure } \\
\text { and equipment } \\
\text { safety and } \\
\text { security }\end{array}$ & $\begin{array}{l}\text { Likelihood of } \\
\text { accidents, i.e. } \\
\text { annual number of } \\
\text { accidents per } \\
\text { respective vehicle } \\
\text { kilometres } \\
\end{array}$ & $10^{\wedge}-5$ & $2 * 10^{\wedge}-3$ & 8 & 7 & $20 \%$ & $>10^{\wedge}-3$ & $\begin{array}{l}\left(10^{\wedge}-4\right)- \\
\left(10^{\wedge}-3\right)\end{array}$ & $<10^{\wedge}-4$ \\
\hline
\end{tabular}




\begin{tabular}{|c|c|c|c|c|c|c|c|c|c|c|c|}
\hline Criterion & $\mathbf{W i}$ & $\begin{array}{l}\text { Indicator } \\
\text { (KPI) }\end{array}$ & Description & $\begin{array}{l}\text { Value } \\
\text { (vij) } \\
\text { ThPA }\end{array}$ & $\begin{array}{l}\text { Value } \\
\text { (vij) } \\
\mathbf{K}+\mathbf{N}\end{array}$ & $\begin{array}{c}\text { Grade } \\
\text { (gij) } \\
\text { ThPA }\end{array}$ & $\begin{array}{c}\text { Grade } \\
\text { (gij) } \\
\mathbf{K}+\mathbf{N}\end{array}$ & wij & $\begin{array}{l}\text { Low } \\
(1-4)\end{array}$ & $\begin{array}{c}\text { Medium } \\
(5-8)\end{array}$ & $\begin{array}{l}\text { High } \\
(9-10)\end{array}$ \\
\hline \multirow{3}{*}{ 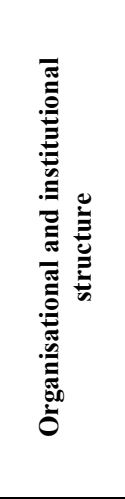 } & \multirow{3}{*}{$15 \%$} & $\begin{array}{l}\text { Independence } \\
\text { of terminal or } \\
\text { interchange } \\
\text { management }\end{array}$ & $\begin{array}{l}\text { Independence from } \\
\text { transport operators } \\
\text { and local actors } \\
\text { (yes/no/partial) }\end{array}$ & yes & partial & 9 & 7 & $50 \%$ & no & partial & yes \\
\hline & & $\begin{array}{l}\text { Fair and equal } \\
\text { access }\end{array}$ & $\begin{array}{l}\text { Whether all } \\
\text { companies have } \\
\text { access to a } \\
\text { terminal/interchange } \\
\text { on equal conditions } \\
\text { (yes/no/partial) }\end{array}$ & yes & yes & 9 & 9 & $40 \%$ & no & partial & yes \\
\hline & & $\begin{array}{l}\text { Institutional } \\
\text { complexity }\end{array}$ & $\begin{array}{l}\text { Number of } \\
\text { institutional levels } \\
\text { involved in the } \\
\text { interchange } \\
\text { planning } \\
\end{array}$ & 4 & 2 & 4 & 8 & $10 \%$ & $>3$ & 2 or 3 & $<2$ \\
\hline \multirow{2}{*}{ 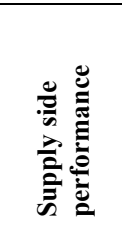 } & \multirow[t]{2}{*}{$20 \%$} & $\begin{array}{l}\text { Employee } \\
\text { productivity }\end{array}$ & $\begin{array}{l}\text { Ratio between flows } \\
\text { and inputs, TEU } \\
\text { transhipped per } \\
\text { employee and year }\end{array}$ & 9324 & 2560 & 7 & 4 & $50 \%$ & $<2880$ & $\begin{array}{l}2880- \\
12000\end{array}$ & $>12000$ \\
\hline & & $\begin{array}{l}\text { Equipment } \\
\text { productivity }\end{array}$ & $\begin{array}{l}\text { Total number of } \\
\text { TEUs lifted per year } \\
\text { and crane }\end{array}$ & 73968 & 15708 & 7 & 4 & $50 \%$ & $<20000$ & $\begin{array}{l}20000- \\
100000\end{array}$ & $>100000$ \\
\hline \multirow{11}{*}{ 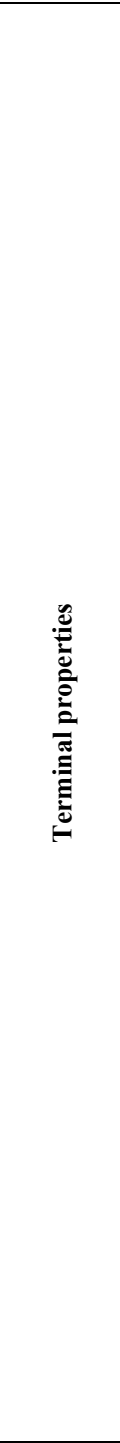 } & \multirow{11}{*}{$25 \%$} & $\begin{array}{l}\text { Saturation } \\
\text { ratio (TEUs) }\end{array}$ & $\begin{array}{l}\text { Ratio between } \\
\text { actual volumes and } \\
\text { maximum capacity } \\
\text { (daily average, } \% \text { ) } \\
\end{array}$ & $66 \%$ & $57 \%$ & 4 & 5 & $10 \%$ & $>60 \%$ & $20-60 \%$ & $<20 \%$ \\
\hline & & $\begin{array}{l}\text { Saturation } \\
\text { ratio (total } \\
\text { cargo } \\
\text { tonnage) } \\
\end{array}$ & $\begin{array}{l}\text { Ratio between } \\
\text { actual volumes and } \\
\text { maximum capacity } \\
\text { (daily average, } \% \text { ) } \\
\end{array}$ & $37 \%$ & $50 \%$ & 7 & 5 & $10 \%$ & $>60 \%$ & $20-60 \%$ & $<20 \%$ \\
\hline & & Expandability & $\begin{array}{l}\text { Potential for } \\
\text { expandability ( } \% \\
\text { increase compared } \\
\text { to today's capacity) } \\
\end{array}$ & $33 \%$ & $10 \%$ & 6 & 2 & $10 \%$ & $<20 \%$ & $20-60 \%$ & $>60 \%$ \\
\hline & & $\begin{array}{l}\text { Distance from } \\
\text { city centre }\end{array}$ & $\begin{array}{l}\text { Number of } \\
\text { kilometres from city } \\
\text { centre to } \\
\text { interchange/terminal }\end{array}$ & $<2$ & 15 & 10 & 6 & $10 \%$ & $>25$ & $5-25$ & $<5$ \\
\hline & & $\begin{array}{l}\text { Distance from } \\
\text { commercial } \\
\text { areas }\end{array}$ & $\begin{array}{l}\text { Number of } \\
\text { kilometres from } \\
\text { terminal to nearest } \\
\text { commercial centre }\end{array}$ & $<5$ & 15 & 10 & 6 & $10 \%$ & $>25$ & $5-25$ & $<5$ \\
\hline & & $\begin{array}{l}\text { Distance from } \\
\text { industrial } \\
\text { zones }\end{array}$ & $\begin{array}{l}\text { Number of } \\
\text { kilometres from } \\
\text { interchange/terminal } \\
\text { to nearest industrial } \\
\text { zone } \\
\end{array}$ & 15 & $<1$ & 6 & 10 & $10 \%$ & $>25$ & $5-25$ & $<5$ \\
\hline & & $\begin{array}{l}\text { Transshipment } \\
\text { time }\end{array}$ & $\begin{array}{l}\text { Time needed for } \\
\text { loading / unloading } \\
\text { per TEU }\end{array}$ & $\begin{array}{c}45 \\
\text { mins }\end{array}$ & $60 \mathrm{mins}$ & 6 & 5 & $10 \%$ & $>60$ & $30-60$ & $<30$ \\
\hline & & $\begin{array}{l}\text { Connection } \\
\text { and distance } \\
\text { to primary } \\
\text { motor-way } \\
\text { network } \\
\end{array}$ & $\begin{array}{l}\text { Direct, indirect or } \\
\text { no access to nearest } \\
\text { highway and } \\
\text { proximity }\end{array}$ & $\begin{array}{l}\text { indirect } \\
(5 \mathrm{Km})\end{array}$ & $\begin{array}{l}\text { direct } \\
(1 \mathrm{Km})\end{array}$ & 8 & 10 & $10 \%$ & $\begin{array}{c}\text { no and } \\
>25\end{array}$ & $\begin{array}{l}\text { indirect } \\
\text { and 5-25 }\end{array}$ & $\begin{array}{c}\text { direct } \\
\text { and }<5\end{array}$ \\
\hline & & $\begin{array}{l}\text { Connection } \\
\text { and distance } \\
\text { to primary } \\
\text { railway } \\
\text { network } \\
\end{array}$ & $\begin{array}{l}\text { Direct, indirect or } \\
\text { no access and } \\
\text { proximity }\end{array}$ & $\begin{array}{l}\text { indirect } \\
(15 \mathrm{Km})\end{array}$ & $\begin{array}{l}\text { direct } \\
(<5 \\
\mathrm{Km})\end{array}$ & 6 & 10 & $10 \%$ & $\begin{array}{c}\text { no and } \\
>25\end{array}$ & $\begin{array}{c}\text { indirect } \\
\text { and 5-25 }\end{array}$ & $\begin{array}{c}\text { direct } \\
\text { and }<5\end{array}$ \\
\hline & & $\begin{array}{l}\text { Connection to } \\
\text { ports }\end{array}$ & $\begin{array}{l}\text { Direct, indirect or } \\
\text { no access and } \\
\text { proximity }\end{array}$ & $\begin{array}{c}\text { direct } \\
(0 \mathrm{Km})\end{array}$ & $\begin{array}{l}\text { indirect } \\
\qquad(15 \\
\mathrm{Km})\end{array}$ & 10 & 6 & $5 \%$ & $\begin{array}{l}\text { no and } \\
>25\end{array}$ & $\begin{array}{l}\text { indirect } \\
\text { and 5-25 }\end{array}$ & $\begin{array}{c}\text { direct } \\
\text { and }<5\end{array}$ \\
\hline & & $\begin{array}{l}\text { Connection to } \\
\text { airports }\end{array}$ & $\begin{array}{l}\text { Direct, indirect or } \\
\text { no access and } \\
\text { proximity }\end{array}$ & $\begin{array}{l}\text { indirect } \\
(15 \mathrm{Km})\end{array}$ & $\begin{array}{l}\text { indirect } \\
(25 \\
\mathrm{Km})\end{array}$ & 6 & 5 & $5 \%$ & $\begin{array}{c}\text { no and } \\
>25\end{array}$ & $\begin{array}{c}\text { indirect } \\
\text { and 5-25 }\end{array}$ & $\begin{array}{c}\text { direct } \\
\text { and }<5\end{array}$ \\
\hline
\end{tabular}




\begin{tabular}{|c|c|c|c|c|c|c|c|c|c|c|c|}
\hline Criterion & Wi & $\begin{array}{l}\text { Indicator } \\
\text { (KPI) }\end{array}$ & Description & $\begin{array}{l}\text { Value } \\
\text { (vij) } \\
\text { ThPA }\end{array}$ & $\begin{array}{l}\text { Value } \\
\text { (vij) } \\
\mathbf{K}+\mathbf{N}\end{array}$ & $\begin{array}{l}\text { Grade } \\
\text { (gij) } \\
\text { ThPA }\end{array}$ & $\begin{array}{l}\text { Grade } \\
\text { (gij) } \\
\text { K+N }\end{array}$ & wij & $\begin{array}{l}\text { Low } \\
(1-4)\end{array}$ & $\begin{array}{c}\text { Medium } \\
(5-8)\end{array}$ & $\begin{array}{l}\text { High } \\
(9-10)\end{array}$ \\
\hline \multirow{7}{*}{ 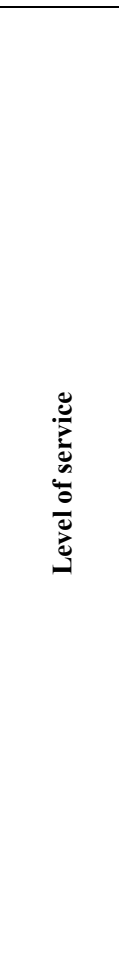 } & \multirow{7}{*}{$25 \%$} & Handling cost & $\begin{array}{l}\text { Average price paid } \\
\text { per } \\
\text { TEU transhipped } \\
(€) \\
\end{array}$ & $\begin{array}{c}100 € / \\
\text { TEU }\end{array}$ & $\begin{array}{c}210 € / \\
\text { TEU }\end{array}$ & 8 & 4 & $20 \%$ & $\begin{array}{l}>200 € \\
/ \text { TEU }\end{array}$ & $\begin{array}{l}100- \\
200 € / \\
\text { TEU }\end{array}$ & $\begin{array}{c}<100 € / \\
\text { TEU }\end{array}$ \\
\hline & & Punctuality & $\begin{array}{l}\text { Percentage of } \\
\text { arrivals / departures } \\
\text { within defined } \\
\text { tolerance for delay }\end{array}$ & $70 \%$ & $100 \%$ & 7 & 10 & $20 \%$ & $<50 \%$ & $50-80 \%$ & $>80 \%$ \\
\hline & & $\begin{array}{l}\text { Origin- } \\
\text { destination } \\
\text { time }\end{array}$ & $\begin{array}{l}\text { Average time for } \\
\text { last mile roundtrip } \\
\text { in city centre }\end{array}$ & $\begin{array}{c}30 \\
\text { mins }\end{array}$ & 60 mins & 8 & 5 & $10 \%$ & $<30$ & $30-60$ & $>60$ \\
\hline & & $\begin{array}{l}\text { Loss and } \\
\text { damage }\end{array}$ & $\begin{array}{l}\text { Percentage of } \\
\text { shipments with loss } \\
\text { or damage }\end{array}$ & $0,50 \%$ & $11,50 \%$ & 9 & 4 & $15 \%$ & $>10 \%$ & $2-10 \%$ & $<2 \%$ \\
\hline & & $\begin{array}{l}\text { Supply chain } \\
\text { visibility }\end{array}$ & $\begin{array}{l}\text { Percentage of } \\
\text { terminal coverage } \\
\text { with GPS, RFID, } \\
\text { CCTV, e-PoDs, } \\
\text { camera surveillance } \\
\text { systems etc }\end{array}$ & partial & yes & 7 & 10 & $15 \%$ & no & partial & yes \\
\hline & & $\begin{array}{l}\text { Information } \\
\text { availability }\end{array}$ & $\begin{array}{l}\text { Existence of real } \\
\text { time information } \\
\text { and alerts inside the } \\
\text { terminal }\end{array}$ & partial & yes & 7 & 10 & $10 \%$ & no & partial & yes \\
\hline & & $\begin{array}{l}\text { Terminal } \\
\text { integration } \\
\text { level }\end{array}$ & $\begin{array}{l}\text { Proximity and } \\
\text { access of terminal to } \\
\text { auxiliary services } \\
\text { (e.g. customs) }\end{array}$ & $\begin{array}{c}0,5 \mathrm{Km} \\
\text { direct }\end{array}$ & $\begin{array}{l}<5 \mathrm{Km} \\
\text { indirect }\end{array}$ & 10 & 8 & $10 \%$ & $\begin{array}{l}>5 \text { and } \\
\text { indirect }\end{array}$ & $\begin{array}{l}1-5 \text { and } \\
\text { direct or } \\
\text { indirect }\end{array}$ & $\begin{array}{c}<1 \text { and } \\
\text { direct }\end{array}$ \\
\hline
\end{tabular}

Each performance index numerical value is estimated through the summing up of the products of indicators' grading by the indicators' weight. Let Wi be the weight for each criterion i (where i is one of the $\mathrm{m}$ qualitative or quantitative criteria mentioned above) and wij is the weight for each respective indicator $\mathrm{j}$ (where $\mathrm{j}=1,2, \ldots, \mathrm{n}$ is the number of indicators in each criterion $\mathrm{i}$ ). Then, given the value vij for each indicator and considering the determined grading scale set by the involved stakeholders or experts, if the grade of each indicator $\mathrm{j}$ is gij, then the partial performance index, PIi, for each criterion, $\mathrm{i}$ (with $\mathrm{j}$ indicators respectively), is estimated through equation 1 :

PIi $=\sum_{j=1}^{n} w i j * g i j$.

In the same way, taking into account the weights and values of all criteria and their respective KPIs, the total performance index (TPI) is estimated through equation 2:

$\mathrm{TPI}=\sum_{\mathrm{i}=1}^{\mathrm{m}} \sum_{\mathrm{j}=1}^{\mathrm{n}} \mathrm{Wi}^{*} \mathrm{wij}^{*} \mathrm{gij}$.

The partial and total performance indices of the two terminals are presented in Table 2.

Table 2. Partial and total performance indices of the two terminals

\begin{tabular}{|l|l|l|}
\hline \multirow{2}{*}{ Criterion } & Performance index \\
\cline { 2 - 3 } & Thessaloniki Port (ThPA & Kuehne+Nagel (K+N) \\
\hline Management policy & 2.6 & 5.6 \\
\hline Organizational and institutional structure & 8.5 & 7.9 \\
\hline Supply side performance & 7 & 4 \\
\hline Terminal properties & 7.1 & 6.45 \\
\hline Level of service & 7.9 & 7.2 \\
\hline All criteria (Total Performance Index - TPI) & $\mathbf{6 . 8 1 5}$ & $\mathbf{6 . 2 3 7 5}$ \\
\hline
\end{tabular}


Results showed that Kuehne+Nagel terminal performs better regarding the first criterion on "Management policy" due to the high multimodality rate and the higher performance on environmental burden, as well as safety and security issues. On the other hand, the Port of Thessaloniki terminal prevails when it comes to all the other criteria due to higher productivity of both personnel and equipment, while also being a little better performing in "terminal properties" and the provided "level of service" to partners and customers. Overall, the Port of Thessaloniki terminal outmaches Kuehne+Nagel terminal by 6.815 to 6.2375. Still, in order to validate the results of the multi criteria analysis, a sensitivity analysis was performed, and the findings are presented in the following section.

\subsection{Sensitivity analysis}

The sensitivity analysis relied on the increase or decrease of each criterion's weight by $10 \%$, and aimed at revealing any modification in the prioritization of the terminals concerning their partial and total performance indices. Each time the emphasis $(+10 \%)$ or the demotion $(-10 \%)$ was set on one criterion, according to the common methodology adopted in similar cases (e.g. Nathanail, 2007). Thus, each criterion's weight was firstly increased and then decreased (one at a time) counterbalancing accordingly the rest of the criteria weights (respectively increased or diminished in order for all criteria weights to sum up to $100 \%$ ). By increasing or decreasing each one of the five criteria weights by $10 \%$ (one at a time) and simultaneously counterbalancing the rest ones' weights, the situation each time is depicted in Table 3.

Table 3. Partial and total performance indices increasing/decreasing criteria weights

\begin{tabular}{|l|l|l|}
\hline \multirow{2}{*}{ Criterion } & \multicolumn{2}{l|}{ Total Performance Index (TPI) } \\
\cline { 2 - 3 } & ThPA & K+N \\
\hline Management policy (+10\%) & 6.3125 & 6.15875 \\
\hline Management policy (-10\%) & 7.3175 & 6.31625 \\
\hline Organizational and institutional structure (+10\%) & 7.05 & 6.44625 \\
\hline Organizational and institutional structure (-10\%) & 6.58 & 6.02875 \\
\hline Supply side performance (+10\%) & 6.8625 & 5.95875 \\
\hline Supply side performance (-10\%) & 6.7675 & 6.51625 \\
\hline Terminal properties (+10\%) & 6.875 & 6.265 \\
\hline Terminal properties (-10\%) & 6.755 & 6.21 \\
\hline Level of service (+10\%) & 6.975 & 6.35875 \\
\hline Level of service (-10\%) & 6.655 & 6.11625 \\
\hline
\end{tabular}

The analysis showed that the modification of each of the criteria weights by $10 \%$ did not affect the prioritization of the terminals, as the Thessaloniki Port terminal still has a higher total performance index compared to Kuehne+Nagel terminal in all cases. In fact, in the majority of the cases, the difference in the TPIs becomes even larger. This outcome proves the stability of the prioritization results produced through the evaluation process, for a weight fluctuation between $-10 \%$ and $+10 \%$.

\subsection{Visualization of the results}

In order the final results on terminal prioritization to be more integrated and representative, the preference ranking organization method for enrichment of evaluations (PROMETHEE) was used. The estimation of the terminals' prioritisation or ranking, following the problem parameters and given their values and weights, is possible through the PROMETHEE and GAIA methods.

The prioritization of the port of Thessaloniki (ThPA) terminal over Kuehne + Nagel $(\mathrm{K}+\mathrm{N})$ 's terminal is further justified through those two terminals' attributes, facts and figures comparison in PROMETHEE. In particular, within Figure 1 (a), the supremacy of ThPA over $\mathrm{K}+\mathrm{N}$ is depicted through PROMETHEE I (partial ranking) of their respective "preference flows" (phi+ and phi-), but also through PROMETHEE II (complete ranking) in Figure 1 (b). 

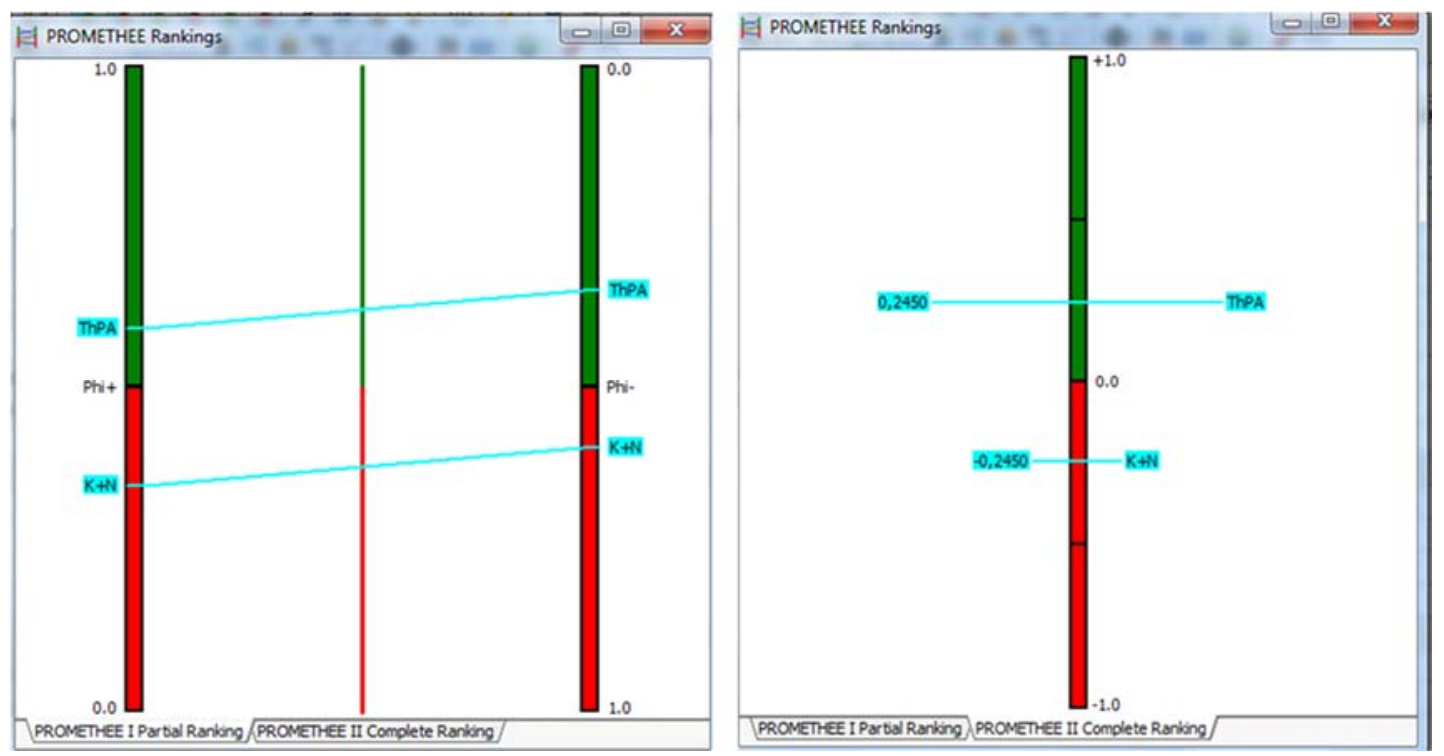

Figure 1. Prioritization of terminals: a) Partial ranking, b) Complete ranking

The preference flows are computed to consolidate the results of the pairwise comparisons of the terminals and to rank them from the best to the worst. The positive preference flow Phi+ measures how much ThPA is preferred to $\mathrm{K}+\mathrm{N}$. It is a global measurement of the strengths of the terminals. The larger $\mathrm{Phi}+$ the better the terminal is. On the other hand, the negative preference flow Phi- measures how much the other terminal $(\mathrm{K}+\mathrm{N})$ is preferred to ThPA. It is a global measurement of the weaknesses of the terminals; the smaller Phi- the better the action. As the two preference flows are consolidating the pairwise comparisons of the actions according to opposite points of view, they usually induce two different rankings on the set of actions. The partial ranking is the intersection of these two rankings. So, ThPA terminal is preferred to $\mathrm{K}+\mathrm{N}$ terminal if and only if the inequations (3) and (4) are valid (which is the situation in our case).

$\mathrm{Phi}+(\mathrm{ThPA}) \geq \mathrm{Phi}+(\mathrm{K}+\mathrm{N})$

Phi- $($ ThPA $) \leq$ Phi- $(\mathrm{K}+\mathrm{N})$

The PROMETHEE II ranking is a complete ranking. This means that both terminals are compared and that the ranking includes no incomparabilities even when comparison is difficult. The resulting ranking can thus be more disputable, especially in the presence of strongly conflicting criteria. The ranking is based on the net preference flow- Phi, which is the balance between the positive (Phi+) and negative (Phi-) preference flows. It combines the two other preference flows in a single summary score. So ThPA is preferred to $\mathrm{K}+\mathrm{N}$ in the PROMETHEE II ranking if and only if ThPA is preferred to $\mathrm{K}+\mathrm{N}$ according to the net preference flow (which is the situation on our occasion).

The PROMETHEE diamond, presented in Figure 2 (a) constitutes an alternate view of the PROMETHEE rankings. Practically, it is an alternative two-dimensional joint representation of both PROMETHEE I and II rankings. The square corresponds to the (Phi+, Phi-) plane where each action is represented by a point. The plane is angled $45^{\circ}$ so that the vertical dimension gives the Phi net flow (summary of Phi+ and Phi- per terminal). Phi+ scores increase from the left to the top corner and Phi- scores increase from the left to the bottom corner. For each action, a cone is drawn from the action position in the plane. As ThPA cone overlaps K+N's cone, it is the preferable one in the PROMETHEE I partial ranking. An advantage of the PROMETHEE diamond is that it is easy to visualize the proximity between Phi+ and Phi- scores globally. In our situation, there is no incomparability and the dominance of ThPA over $\mathrm{K}+\mathrm{N}$ is clear as both coefficients (Phi+ and Phi-) of the first are bigger than the respective ones of the second. 


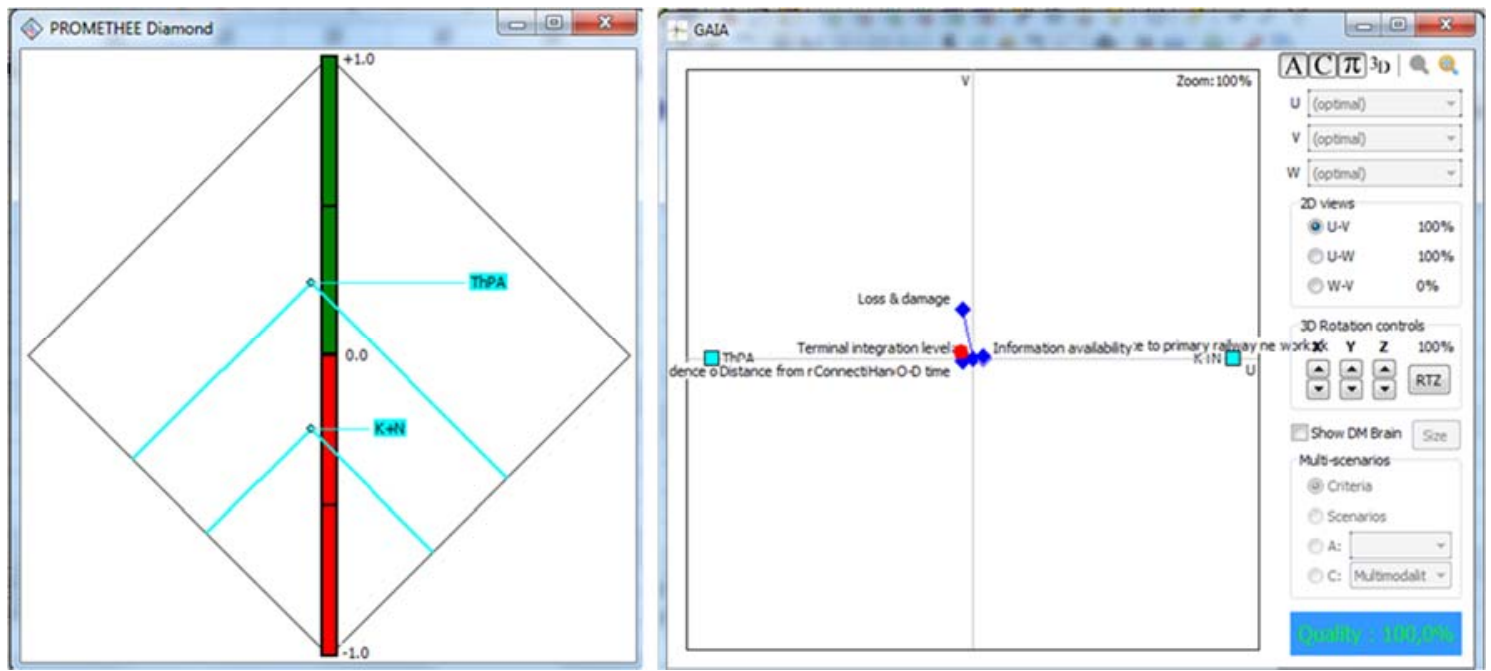

Figure 2. Ranking of terminals: a) PROMETHEE diamond, b) GAIA visual analysis

Finally, in Figure 2 (b), GAIA uses a dimension-reduction technique that is borrowed from statistical data analysis. This technique is called the principal components analysis (PCA). PCA allows the definition of a series of orthogonal dimensions (principal components) that keep as much information as possible on the relative positions of the actions in the $\mathrm{k}$-dimensional space.

In the original GAIA method the two first principal components (named $\mathrm{U}$ and $\mathrm{V}$ ) are computed and displayed in the GAIA plane, which is the best two-dimensional representation of the multi-criteria problem. It retains the maximum possible quantity of information from the k-dimensional representation. This quantity of information can be measured and is usually called D. In Visual PROMETHEE it appears under the name "Quality" in the GAIA window (In this case the quantity of information contained in the plane is equal to $100 \%$, as shown in the right bottom corner of the GAIA window in Visual PROMETHEE). In GAIA visual analysis, the KPIs are represented by axes drawn from the center of the plane. KPIs expressing similar preferences are represented by axes oriented in similar directions, while KPIs expressing conflicting (opposite) preferences are represented by axes oriented in opposite directions. The length of a KPI axis is representative of its relative discriminating power: the longer the axis the more discriminating the criterion. Due to the large number of KPIs, it is difficult to clearly discriminate all KPIs. However, it is recorded that the vertex of each KPI is destined to the prevailing terminal (ThPA or $\mathrm{K}+\mathrm{N})$ ) i.e. almost all of the KPIs of the "Management policy" criterion are in favour of K+N's terminal, while the majority of the KPIs of the other four criteria are closer to the ThPA's terminal.

\section{Summary and conclusions}

This paper proposed a multi-stakeholder multi-criteria evaluation framework, which can be used for the assessment of the last mile performance of urban freight terminals. Towards this direction, a comparative analysis was conducted addressing two Greek urban intermodal freight terminals: the port of Thessaloniki (ThPA) and Kuehne+Nagel $(\mathrm{K}+\mathrm{N})$ distribution center. The assessment of the terminals' performance relied on a tailored multi-criteria Key Performance Indicator (KPI)-based evaluation framework, whereas the selection and significance of the incorporated criteria and KPI's was predetermined by the relevant responsible stakeholders, who imposed their viewpoint through an analytic hierarchy process.

Results showed that ThPA was ranked first according to its performance pertaining to the role of an intermodal interchange; still, K+N's performance index was only $8.5 \%$ lower than ThPA's, while in specific KPI's it seems that it performs in a better way. The prevailing ranking of ThPA versus $\mathrm{K}+\mathrm{N}$ was further tested with the use of a sensitivity analysis, while the final outcome of this study was additionally justified through the PROMETHEE method.

Even if other processes or methods could have been implemented for the comparison of the two terminals, still, the selection of the multi-stakeholder multi-criteria evaluation process, allowed an objective, integrated and holistic approach, and increased significantly the validity of the results. 
Concluding, the evaluation framework introduced by this study, can be adopted by stakeholders, who are involved mainly in the last mile distribution, in order to support future decisions that will be made for strategic planning purposes and will be affected by various criteria, emerging trends and trade-offs.

\section{References}

1. Andersen J., Eidhammer O., Osland, O., Parra L. and Adamos, G. (2010) Interconnections between short and long-distance transport networks: Structure of interface and existing indicators. Deliverable 3.1. CLOSER - Connecting LOng and Short-distance networks for Efficient tRansport.

2. Andersen, J., Eidhammer, O., Gogas, M., Papoutsis, K. and Nathanail, E. (2014) Demonstration assessments. Deliverable 5.1. STRAIGHTSOL - STRAtegies and measures for smarter urban freiGHT SOLutions.

3. Chen, M.K. and Wang, S. (2010) The critical factors of success for information service industry in developing international market: Using analytic hierarchy process (AHP) approach. Expert Systems with Applications, Vol. 37, 2010, pp. 694-704.

4. Christiansen, P., Johansen, B.G., Andersen, J. and Eidhammer, O. (2012) Case studies: Results and synthesis. Deliverable 5.2. CLOSER - Connecting LOng and Short-distance networks for Efficient tRansport.

5. European Center for Government Transformation, (2015) Boosting innovation in cities to deliver better public services - A view from tomorrow's leaders. College of Europe student case studies, Final report.

6. European Commission (2014) Living well, within the limits of our planet. 7th EAP — The New General Union Environment Action Programme to 2020.

7. Gogas, M. and Nathanail, E. (2014) Multilevel multicriteria design of intermodal transport Freight Center networks. International Conference on Engineering and Applied Sciences Optimization (OPTi 2014), Kos Island, Greece.

8. Järvi, T. and Nagel, I. (2013) Guidance and recommendations for interconnection between long distance and local/regional passenger transport. Deliverable 6.1. CLOSER - Connecting LOng and Short-distance networks for Efficient tRansport.

9. Li, S. and Li, J.Z. (2009) Hybridising human judgment, AHP, simulation and a fuzzy expert system for strategy formulation under uncertainty. Expert Systems with Applications, Vol. 36 2009, 55575564.

10. Nathanail, E. and Gogas, M. (2005) Spatial planning - Development of nodal points and terminals. Deliverable 4. IMONODE - Efficient Integration of cargo transport MOdes and NODEs in CADSES area.

11. Nathanail, E. (2007) Developing an integrated logistics terminal network in the CADSES area. Transition Studies Review, May 2007, Volume 14, Issue 1, pp 125-146.

12. Nathanail, E.G., Gogas, M.A. and Papoutsis, K.N. (2014) Investigation of Stakeholders' View towards the introduction of ICT in Supply Chain using Analytic Hierarchy Process. Journal of Traffic and Logistics Engineering, Vol. 2 No. 2, pp. 113-119.

13. Perez, D.H. (2013) Supply Chain Roadmap: aligning supply chain with business strategy. ISBN 9781494200497.

14. Rodrigue, J.P., Comtois, C. and Slack, B. (2009) The "Last Mile" in Freight Distribution. The Geography of Transport Systems (2nd ed.), Routledge. p. 212. ISBN 978-0-415-48323-0.

15. Saaty, T. (1972) An eigenvalue allocation model for prioritization and planning. In working paper Energy Management and Policy Center, University of Pennsylvania, 1972.

16. Saaty, T. (1977) A scaling method for priorities in hierarchical structures. Journal of Mathematical Psychology, Vol. 15 1977, pp. 234-281.

17. Scott, M. (2009) Improving Freight Movement in Delaware Central Business Districts. Institute for Public Administration, University of Delaware.

18. Taniguchi, E., Thompson, R.G. and Yamada, T. (1999) Modeling city logistics. In: City Logistics I (E. Taniguchi and R.G. Thompson, eds.), Institute of Systems Science Research, Kyoto, pp. 3-37.

19. Woudsma, C., Jensen, J., Karoglou, P. and Maoh, H. (2007) Logistics land use and the city: A spatialtemporal modeling approach. Transportation Research Part E, 44, 277-297.

20. Zahir, S. (1999) Clusters in group: Decision making in the vector space formulation of the analytic hierarchy process. European Journal of Operational Research 112: 620-634. 